\title{
Influence of mouse strain, infective dose and larval burden in the brain on activity in Toxocara-infected mice
}

\author{
D.M. Cox and C.V. Holland* \\ Department of Zoology, Trinity College, Dublin 2, Ireland
}

\begin{abstract}
Outbred LACA mice and inbred NIH mice were administered low (100 ova), medium (1000 ova), high (3000 ova) and trickle $(4 \times 250$ ova) doses of Toxocara canis ova and the effect of infection on activity was examined with respect to: (i) the dose of ova administered and (ii) the number of larvae recovered from the brain. Larval recovery from the brain was significantly reduced in NIH mice compared to LACA mice for the 1000, 3000 and trickle doses. Mice from each strain were divided into larval intensity groupings based upon the number of larvae recovered from their brain. Activity for each mouse was measured preand post-infection by observing its behaviour in the home cage. Activity was assessed by monitoring six different independent categories of murine behaviour - ambulation, grooming, rearing, digging, climbing and immobility. Within each behavioural category, the duration of time spent at each behaviour per mouse within one thousandth of a second, the number of short bouts performed and the number of long bouts of behaviour performed were recorded over a 20 min period. Activity of LACA and NIH mice differed prior to infection. LACA mice spent more time immobile compared to NIH mice, which ambulated and climbed more. Variations in activity were also observed between groups of mice prior to infection. The effect of infection differed by strain, by dose and by larval intensity. Post-infection LACA mice became more immobile and ambulated less. NIH mice showed reduced immobility, but while ambulation decreased digging and climbing increased post-infection. Short bouts of activity remained unchanged among LACA mice post-infection but showed an increase for some behaviours in NIH mice.
\end{abstract}

\section{Introduction}

Parasites can have profound effects on host behaviour (Barnard \& Behnke, 1990). These effects can include alterations in host behaviour, which can facilitate parasite transmission, and changes, which are likely to be a consequence of non-adaptive pathology. Toxocara canis in the mouse provides a useful host-parasite system to select for the study of parasite-altered host behaviour. Adult worms attain maturity in the intestine of canids but second stage larvae can infect a wide range of paratenic hosts including humans and mice. In these abnormal hosts, the immature stages of T. canis undergo

*Fax: +35316778094

E-mail: cholland@mail.tcd.ie a somatic migration through the organs of the body but fail to reach maturity as adult worms in the intestine. If ingested by an appropriate definitive host, larvae in murine tissue can develop to adulthood.

Toxocara is known to produce several clinical entities associated with widespread tissue invasion and eye involvement but the neurotrophic behaviour of the larvae, which results in a greater concentration of parasites in the brain (Dunsmore et al., 1983; Skerrett \& Holland, 1997) as the infection progresses may be of particular relevance to parasite-altered host behaviour. The model system in mice provides several opportunities for investigation (Holland, 1997). Firstly, it can act as a model for human infection and observed changes in murine behaviour, particularly at low dose levels, may be 
Table 1. The mean number of larvae $( \pm \mathrm{SE})$ recovered from the brains of outbred LACA mice and inbred NIH mice infected with four doses of Toxocara canis ova.

\begin{tabular}{|c|c|c|c|c|c|c|c|c|c|}
\hline Dose & & LACA & LACA $\%$ of dose & Dose & & $\mathrm{NIH}$ & $\mathrm{NIH} \%$ of dose & $\mathrm{t}$ statistic & $P$ value \\
\hline $\begin{array}{l}1000 \\
n=8\end{array}$ & $\begin{array}{l}\text { Mean } \\
\text { Median } \\
\text { Range }\end{array}$ & $\begin{array}{c}59.8 \pm 15.2 \\
45.5 \\
14-142\end{array}$ & 5.9 & $\begin{array}{c}1000 \\
n=6\end{array}$ & $\begin{array}{l}\text { Mean } \\
\text { Median } \\
\text { Range }\end{array}$ & $\begin{array}{c}10.8 \pm 2.7 \\
10.5 \\
3-20\end{array}$ & 1.1 & -3.202 & $\leq 0.015$ \\
\hline $\begin{array}{l}3000 \\
n=9\end{array}$ & $\begin{array}{l}\text { Mean } \\
\text { Median } \\
\text { Range }\end{array}$ & $\begin{array}{c}183.1 \pm 49.7 \\
123 \\
66-157\end{array}$ & 6.1 & $\begin{array}{c}3000 \\
\mathrm{n}=4\end{array}$ & $\begin{array}{l}\text { Mean } \\
\text { Median } \\
\text { Range }\end{array}$ & $\begin{array}{c}39.2 \pm 5.7 \\
36.5 \\
30-54\end{array}$ & 1.3 & -2.872 & $\leq 0.020$ \\
\hline $\begin{array}{l}\text { Trickle } \\
\mathrm{n}=7\end{array}$ & $\begin{array}{l}\text { Mean } \\
\text { Median } \\
\text { Range }\end{array}$ & $\begin{array}{c}35.5 \pm 5.9 \\
34 \\
12-55\end{array}$ & 3.5 & $\begin{array}{l}\text { Trickle } \\
\mathrm{n}=6\end{array}$ & $\begin{array}{l}\text { Mean } \\
\text { Median } \\
\text { Range }\end{array}$ & $\begin{array}{c}4.8 \pm 1.3 \\
4.5 \\
0-9\end{array}$ & 0.4 & -5.202 & $\leq 0.002$ \\
\hline
\end{tabular}

relevant to humans with toxocariasis. Secondly, it is ecologically significant, in that it can be used to test the hypothesis that parasite-altered host behaviour may contribute to increased predation of infected paratenic hosts and hence enhanced transmission of the parasite. Alteration in activity is one of the most widespread changes observed in infected hosts under laboratory and field conditions (Moore \& Gotelli, 1990). In some cases both an increase and a decrease in activity in similar hosts has been hypothesized to influence host predation, which may benefit the parasite. Rau (1983) suggested that a reduction in ambulation and exploration by mice infected with Trichinella spiralis would increase their risk of predation, as these mice would be less familiar with their environment. In contrast, Hay et al. (1986) observed hyperactivity in mice infected with Toxocara canis and concluded that this could increase the risk of transmission by making the mice more conspicuous to a potential predator.

It is important to assess the effect of a parasite upon host baseline activity before embarking upon studies of more specific behaviours such as anxiety, learning and memory. The experiment described in this paper sought to explore the following: (i) to compare the baseline activity levels of an inbred and an outbred strain of mouse prior to infection with T. canis; (ii) to investigate the potential changes in activity of the two strains of mice after infection with four doses of T. canis ova; (iii) to establish the relationship between dose administered and larval recovery in the brain and to compare larval accumulation between the two strains of mice; and (iv) to investigate if any of the observed changes in activity are related to dose administered and larval intensity in the brain. Three novel elements to the study should be emphasized compared to previous work on activity in Toxocara-infected mice. Firstly, two strains of mice received one of four doses of Toxocara ova compared to a single dose. Secondly, pre-infection measurements of activity were made to take account of behavioural variability between individual mice and groups of mice and differences between pre- and post-infection measures for each activity were analysed. Thirdly, potential changes in murine activity post-infection were explored in terms of both dose administered and larval intensity in the brain.

\section{Materials and methods}

\section{Mouse maintenance}

Fifty outbred (LACA) male mice and 40 inbred (NIH) male mice, aged between 4 and 5 weeks were used in the experiment. The mice were housed in an animal maintenance room in single cages measuring $35 \times 15 \times$ $13 \mathrm{~cm}$. The room was illuminated by a 200 lux bulb, which operated on a $12 \mathrm{~h}$ daily cycle (0800 lights on 2000 lights off). The room was kept at a constant temperature of $22^{\circ} \mathrm{C} \pm 2{ }^{\circ} \mathrm{C}$ and humidity of $50 \pm 10 \%$ $\mathrm{RH}$ which was monitored daily. An automatic fan circulated a continuous stream of warm air around the room. The mice were fed Redmills Commercial Rodent Nuts and free access to food and water was available at all times. The mice were weighed individually and grouped according to their weight, placing similar weights together. LACA mice weighed between 26.1 and $43.2 \mathrm{~g}$ and NIH mice 21.9 to $28.3 \mathrm{~g}$. Each mouse was then assigned to one of five groups. For identification purposes, each group was assigned a number. The mice were habituated to these conditions for 2 weeks before behavioural testing was carried out.

\section{Infection of mice}

The doses of T. canis ova administered were 100 (low dose), 1000 (medium dose), 1000 over 28 days, i.e. 250 per week (trickle) and 3000 (high). Four of the groups of mice from each strain were randomly chosen and infected orally by stomach intubation with one of the four infection doses suspended in $0.2 \mathrm{ml}$ of distilled water. The control groups were sham-inoculated with distilled water. The mice were monitored hourly after infection for post-inocula trauma or ill effects. The infection was allowed to establish over a 30-day period before postinfection behavioural testing began. Previous research had demonstrated that in mice infected with $T$. canis ova the larvae reach the brain within 2 days and stabilize at this site between days 35 and 45 (Burren, 1971). It was considered that the behavioural effects due to the presence of the larvae in the brain would be most conspicuous during this time. 
Table 2. Differences in activity in LACA mice before and after infection with Toxocara canis analysed by dose and larval intensity.

\begin{tabular}{lllc}
\hline Behaviour & \multicolumn{1}{c}{ Measurement } & By dose & $\begin{array}{c}\text { By larval } \\
\text { intensity }\end{array}$ \\
\hline \multirow{2}{*}{ Grooming } & Pre infection & $\mathrm{df}=4,41$ & $\mathrm{df}=3,41$ \\
Immobility & Pre short bouts & $3^{*}$ & $\mathrm{NS}$ \\
& Post infection & $9.3^{* * * * *}$ & $4^{*}$ \\
& Post short bouts & $3^{*}$ & $3.1^{*}$ \\
& Post long bouts & $7^{* *}$ & $\mathrm{NS}$ \\
& Difference short bouts & $6^{* *}$ & $\mathrm{NS}$ \\
& Difference long bouts & $3^{*}$ & $\mathrm{NS}$ \\
Ambulation & Post infection & $5^{* *}$ & $\mathrm{NS}$ \\
& Post long bouts & $9.2^{* * * *}$ & $\mathrm{NS}$ \\
Digging & Pre short bouts & $\mathrm{NS}$ & $3.3^{*}$ \\
Climbing & Pre infection & $\mathrm{NS}$ & $5^{* *}$ \\
& Pre long bouts & $\mathrm{NS}$ & $3.4^{*}$ \\
\hline
\end{tabular}

Numbers by dose and larval intensity $=\mathrm{F}$ ratio derived from one-way ANOVA.

${ }^{*} P \leq 0.05 ;{ }^{* *} P \leq 0.01 ;{ }^{* * *} P \leq 0.001 ;{ }^{* * *} P \leq 0.0001$.

Table 3. Differences in activity in NIH mice before and after infection with Toxocara canis analysed by dose and larval intensity.

\begin{tabular}{llcc}
\hline \multirow{3}{*}{ Behaviour } & \multicolumn{1}{c}{ Measurement } & By dose & $\begin{array}{c}\text { By larval } \\
\text { intensity }\end{array}$ \\
\hline \multirow{4}{*}{ Immobility } & Pre infection $=4,38$ & $\mathrm{df}=2,27$ \\
& Post infection & $4.8^{* *}$ & $\mathrm{NS}$ \\
& Post long bouts & $5.5^{* *}$ & $6^{* *}$ \\
& Difference infection & $7^{* * *}$ & $\mathrm{NS}$ \\
& Difference long bouts & $6^{* *}$ & $3.4^{*}$ \\
Ambulation & Post infection & $\mathrm{NS}$ & $3.4^{*}$ \\
& Post short bouts & $8^{* * * *}$ & $6^{* *}$ \\
& Difference short bouts & $4^{*}$ & $\mathrm{NS}$ \\
& & & \\
Rearing & Post short bouts & $8^{* * * *}$ & $4^{*}$ \\
& Post long bouts & $3.2^{*}$ & $\mathrm{NS}$ \\
& Difference short bouts & $3.1^{*}$ & $\mathrm{NS}$ \\
& & & \\
& Pre long bouts & $\mathrm{NS}$ & $4.2^{* *}$ \\
& Post infection & $5^{* *}$ & $10.3^{* * *}$ \\
& Post short bouts & $6^{* *}$ & $9^{* *}$ \\
& Post long bouts & $\mathrm{NS}$ & $6^{* *}$ \\
& Difference infection & $3^{*}$ & $5.1^{*}$ \\
& Difference short bouts & $4.4^{* *}$ & $6^{* *}$ \\
& Post infection & $4^{*}$ & $6^{* *}$ \\
& Post short bouts & $3.2^{*}$ & $\mathrm{NS}$ \\
& Post long bouts & $6^{* *}$ & $6^{* *}$ \\
& Difference & $3.2^{*}$ & $\mathrm{NS}$ \\
& Difference long bouts & $7.1^{* * *}$ & $4.5^{*}$ \\
\hline
\end{tabular}

Numbers by dose and larval intensity $=\mathrm{F}$ ratio derived from one-way ANOVA.

${ }^{*} P \leq 0.05 ;{ }^{* *} P \leq 0.01 ;{ }^{* *} P \leq 0.001 ;{ }^{* * *} P \leq 0.0001$.

\section{Behavioural testing}

The first behavioural testing was carried out prior to infection on day 15 of habituation. Mice were infected on day 25 and on day 55 post-infection behavioural testing was repeated. Activity for each mouse was measured by observing its behaviour in the home cage. Each cage was made of polypropylene $(33 \times 15 \times 13 \mathrm{~cm})$ and had a stainless steel wire lid on top which held a water bottle and commercial rodent chow. The cage bottom was covered with $1-2 \mathrm{~cm}$ moss peat.

Activity was assessed by monitoring six different independent categories of murine behaviour, which were independently timed and categorized. The experiment was run on two consecutive days for each strain of mice between $1200 \mathrm{~h}$ and $2000 \mathrm{~h}$ in silence with food and water restricted. Before each of the mice was tested, a mild stimulating event was performed. Two structures made from sheet aluminium, which were constructed to fit into the animal's home cage, were placed around the interior walls once the wire top lid had been removed. This formed a $45 \mathrm{~cm}$ high, open topped enclosure which was unfamiliar to the animals. This structure was left in place for a $40 \mathrm{~s}$ period after which it was removed and replaced with the familiar wire top lid. The cage was then transferred to the testing position and the behaviour of the mouse was recorded over a 20 min period on videotape using a Sony Camcorder Recorder attached to a video monitor which allowed the animal's behaviour to be observed from a position in which the animal could not see the experimenter. The data were collected and recorded by analysing the prerecorded videos in which the infection status of each group was unknown.

The six behavioural parameters of murine behaviour chosen for investigation were ambulation (general movement, sometimes described as locomotion), grooming, rearing, digging, climbing and immobility. The behaviours included within these six broad categories of behaviour are as follows (see Hutchinson et al., 1980).

Ambulation: walk, run, jump, roll, circle, stretch.

Grooming: bite coat, lick coat, wash face, scratch, wash genitals, chew tail.

Rearing: stand on cage (front feet raised off floor, placed on sides of cage), straight rear (front feet raised off floor and held close to body).

Digging: dig (bedding scrapped back with forepaws and kicked back with hind paws), push dig (sawdust pushed forward with forepaws).

Immobile: stomach (animal is on stomach, head erect), stand still (animal stands, body off floor).

Climbing: on bars - animal climbs onto bars of cage in upside down position.

Within each behavioural category the following measurements were recorded: (i) the duration of time spent at each behaviour per mouse within one thousandth of a second; (ii) the percentage of time spent at each behaviour per mouse; (iii) the number of short bouts (lasting 0-2 s) of behaviour performed; and (iv) the number of long bouts ( $>2 \mathrm{~s}$ ) performed.

An appropriate computer programme stored the 
movements of the animal over the $20 \mathrm{~min}$ period and produced an individual summary for each mouse. Increases in the number of short bouts performed have been described as an indication of behaviour analagous to hyperactivity (Hay et al., 1986).

\section{Larval counts}

The mice in each experiment were killed by cervical dislocation on day 60 post-infection following the last behavioural experiment. The brain was removed using a fine scissors and forceps. The Baermann procedure (Pritchard \& Kruse, 1982) was carried out in order to count the total number of larvae recovered from the whole brain of individual mice. The procedure for the examination of brain material is the same as that described in Cox \& Holland (1998).

\section{Statistical methods}

All statistical tests were carried out at the $95 \%$ confidence limit. In instances where the data was skewed, a log transformation was performed in order to normalize the data. Inter-group differences by dose and by larval intensity grouping were explored by means of one-way analysis of variance (ANOVA). The $\mathrm{F}$ ratios generated from these analyses are provided in tables 2 and 3 for LACA and NIH mice respectively. Only statistically significant ratios are provided for one or both dose and larval intensity analyses. Separate group comparisons were made using least significant difference (LSD) post hoc tests and these $P$ values are reported in the text.

Mean differences between pre- and post-infection behaviours were generated and are compared in three ways. Firstly, ANOVA was used to compare the mean difference between the groups by dose and by larval
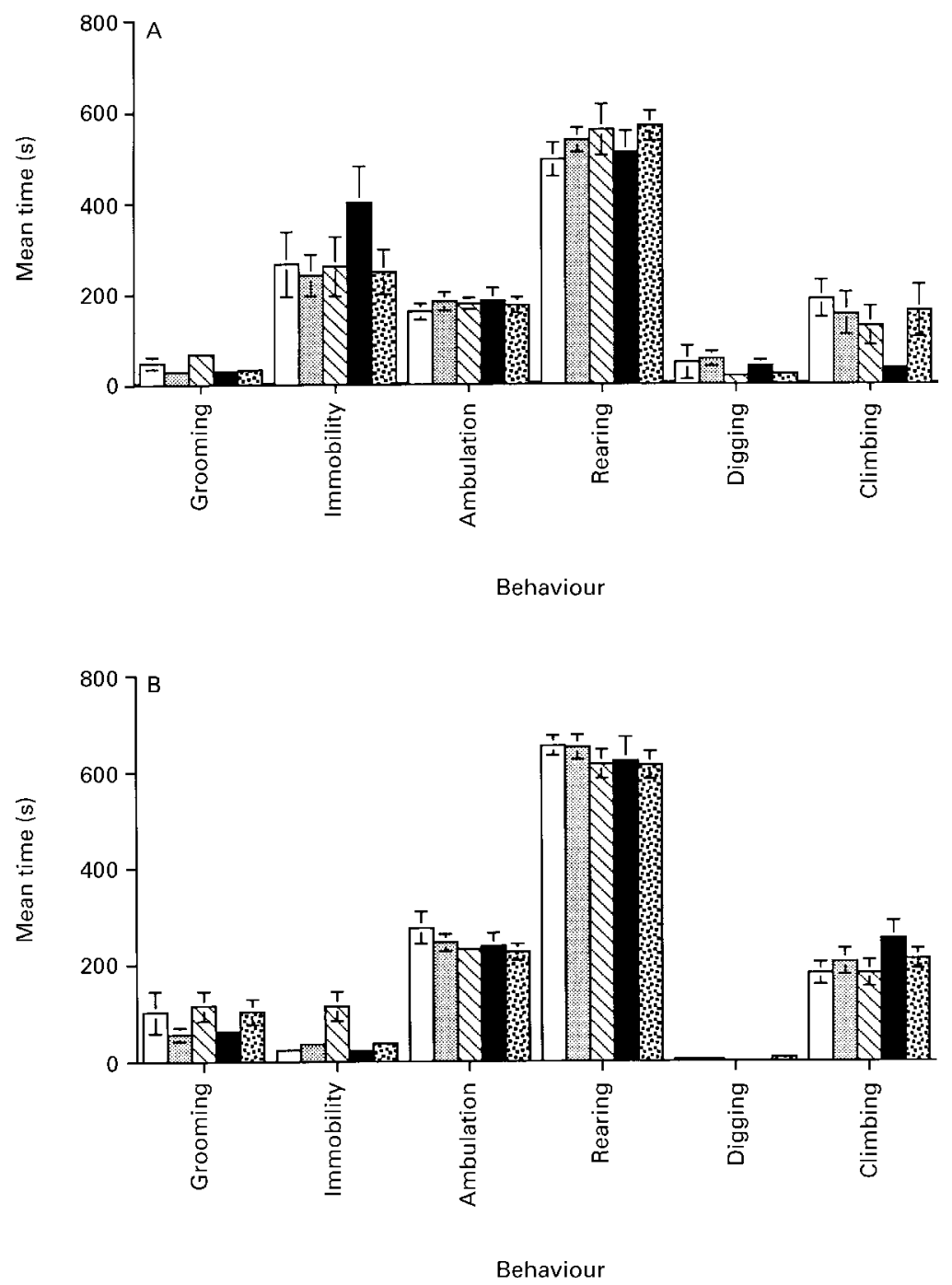

Fig. 1. The mean time $( \pm \mathrm{SE})$ spent at each murine behaviour pre-infection with Toxocara canis ova by LACA mice (A) and NIH mice (B). Dose group: $\square$, control; $\square, 100 ; \mathbb{\mathbb { N }}, 1000$; 3000; 国, trickle. 

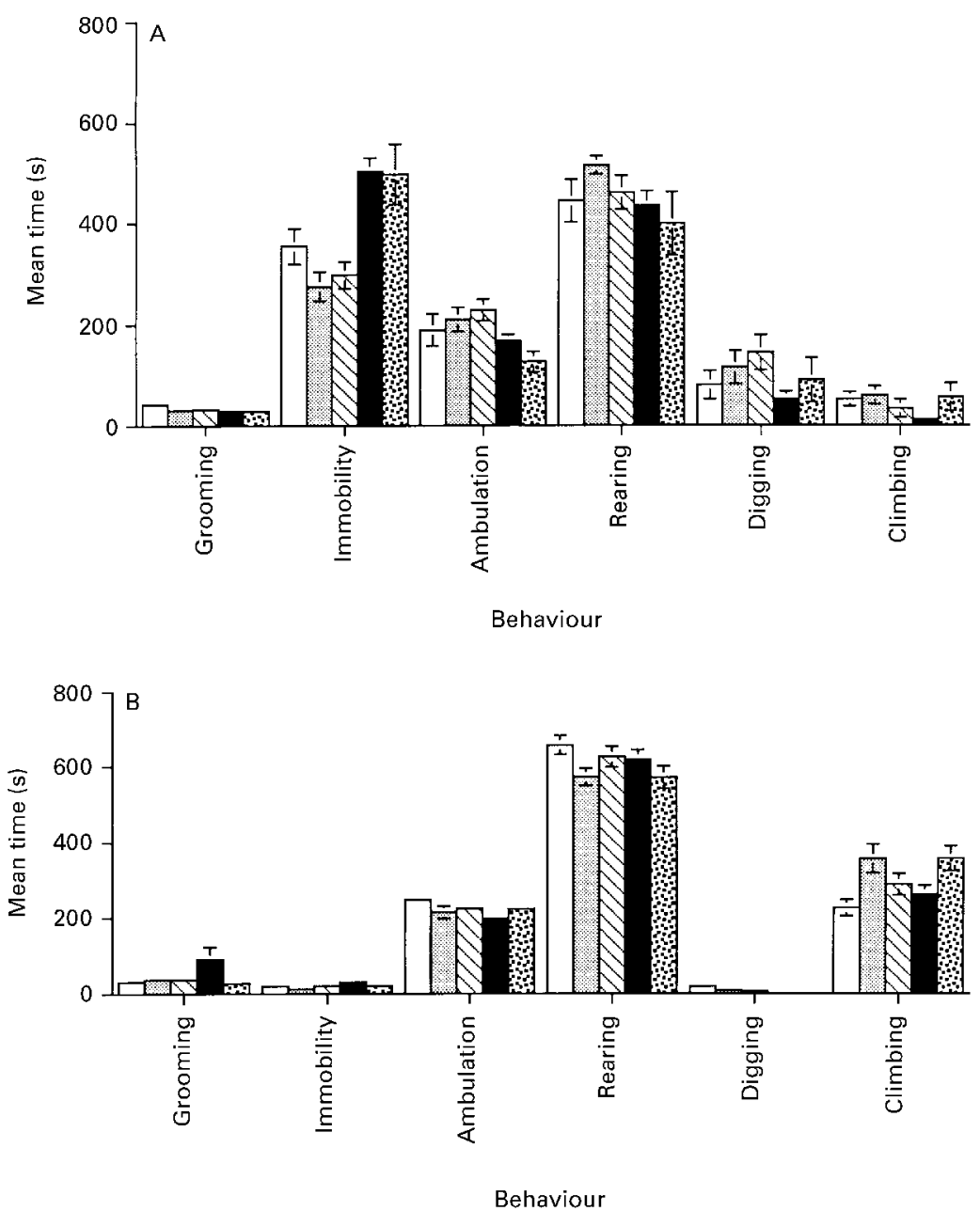

Fig. 2. The mean time $( \pm \mathrm{SE})$ spent at each murine behaviour post-infection with Toxocara canis

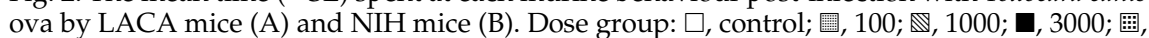
trickle.

intensity and those comparisons which were significantly different are also provided in tables 2 and 3 and labelled as differences. Secondly the trends for each behaviour for LACA mice and NIH mice are shown visually in figs 3-8. Finally, intra-group differences were also compared (so that each mouse acted as its own control) by means of paired t-tests to show if groups differed significantly after infection. This comparison was made by dose group only and the stars provided on the figs 3-8 indicate any significant differences. The mean number of larvae recovered from the individual mouse brains for each dose were compared for LACA and NIH mice using the student's t-test.

\section{Results}

\section{Larval recovery}

The mean number of larvae recovered from the brains of individual mice and the percentage larval recovery expressed in terms of the total dose administered are compared for the two strains of mice infected with each of the four doses of T. canis ova (table 1). At the 100 dose, larval recovery both in terms of numbers and as a percentage of dose are similar for the two strains of mice but at the higher and trickle doses the larval recovery is significantly higher amongst LACA mice compared to NIH mice and this is particularly pronounced for the trickle infections (table 1).

On the basis of the number of larvae recovered from individual brains of mice, the infected mice were divided into larval intensity groups. The LACA strain mice which received an infective dose but contained no larvae (two from the 100 dose) were included with mice containing up to 15 larvae $(n=11$; mean \pm SD $5.8 \pm$ 4.9) and defined as low intensity infections. This included nine 100 dose mice and one 1000 dose and one trickle dose mouse respectively. Mice which contained 27 to 55 larvae were defined as moderate intensity infections $\quad(n=10 ; \quad$ mean $\pm S D \quad 38.7 \pm 11.5)$. This included four 1000 dose mice and six trickle dose mice. Mice which contained 66 to 557 larvae in the brain were defined as heavy intensity infections $(n=12$; mean $\pm S D$ 

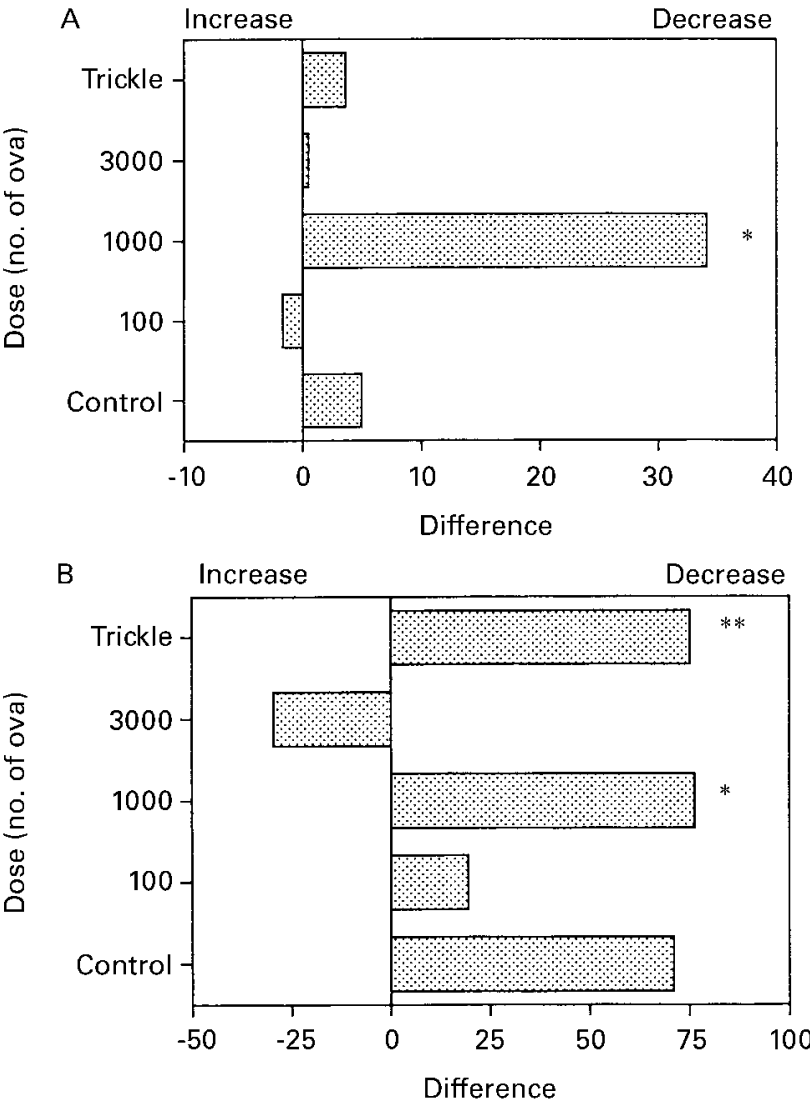

Fig. 3. The mean difference in the time spent grooming for each dose group pre- and post-infection with Toxocara canis by LACA mice (A) and NIH mice (B). ${ }^{*} P \leq 0.05 ;{ }^{*} P \leq 0.01$.

$169.3 \pm 131.9)$. This included nine 3000 dose mice and three 1000 dose mice.

For the NIH mice, fewer data were available on larval counts - for the total number of mice used in the experiment only 21 had larval counts from the brain (table 1). For this reason and due to the lower number of larvae recovered from the NIH mice brains only two larval intensity categories were devised for the NIH mice as compared to three for the LACA mice. Mice which had received an infective dose but contained no larvae were included with mice containing up to nine larvae $(\mathrm{n}=14$; mean \pm SD $4.35 \pm 2.8$ ) and defined as low intensity infections. This included five 100 dose mice, six trickle dose mice and three 1000 dose mice. Mice which contained 13 to 54 larvae were defined as moderate intensity infections $(n=7$; mean \pm SD $29.4 \pm 13.7)$.

\section{Differences in activity of LACA and NIH mice pre-infection}

Figure 1 shows that the activity of inbred and outbred mice differ before infection. LACA mice spent most of their time rearing followed by being immobile (fig. 1A). Mice spent comparatively little time digging and grooming. In contrast, NIH mice spent much less time being immobile and more time ambulating and climbing (fig. 1B). Digging was virtually non existent amongst NIH mice pre-infection.

For both strains of mice, groups differed in their behaviour pre-infection. Comparisons between groups of mice, which would receive different doses or were assigned to different larval intensity groupings, revealed several categories of activity for which pre-infection patterns differed. For LACA mice, aspects of grooming, immobility, digging and climbing behaviour differed significantly between the groups pre-infection (table 2). For NIH mice, aspects of immobility and digging differed significantly between the groups pre-infection (table 3).

Differences in activity of LACA and NIH mice post-infection LACA mice

Post-infection, LACA mice showed no significant differences in overall patterns of grooming, rearing, digging and climbing, between either the five dose groups or the four intensity groups although there was a trend for digging to increase and climbing to decrease (fig. 2A). Immobility did show a marked increase postinfection and this was particularly pronounced for the 3000 dose group and the trickle group which were significantly different $(P \leq 0.004)$ from all other groups except each other (table 2; fig. 2A). In the analysis by larval intensity, the high intensity group showed significantly more immobility compared to the low intensity group $(P<0.006)$ (table 2$)$. Ambulation for LACA mice also showed significant changes post-infection with an increase for the control, 100 and 1000 groups and a decrease for the 3000 dose and the trickle dose (which differed significantly from all other groups) $(P \leq 0.04)$.

Differences in short and long bouts were also observed post-infection for immobility and ambulation (table 2). Short bouts of immobility were increased in the 1000 and 3000 dose groups compared to the controls $(P \leq$ 0.02) as were long bouts of immobility for the 3000 dose and the trickle dose compared to all other groups except each other $(P \leq 0.002)$. Short bouts of immobility also increased significantly in the high larval intensity group compared to the control $(P \leq 0.003)$ as did long bouts for this group compared to the control and the low larval intensity group $(P \leq 0.041)$. Long bouts of ambulation were reduced significantly in the trickle group compared to all other dose groups $(P \leq 0.0002)$.

\section{NIH mice}

Post-infection, NIH mice showed no significant difference in grooming between either the five dose groups or the four intensity groups. Differences were observed for overall patterns of immobility, ambulation, digging and climbing (fig. 2B). Immobility was low in $\mathrm{NIH}$ mice compared to LACA mice infection but postinfection time spent being immobile was reduced even further (fig. 2B). The moderate larval intensity group showed a significant reduction compared to the low intensity group $(P \leq 0.002)$. Ambulation was reduced post-infection in all infection groups but not the control (fig. 2B) and this reduction was significant for the moderate larval intensity group compared to the control 

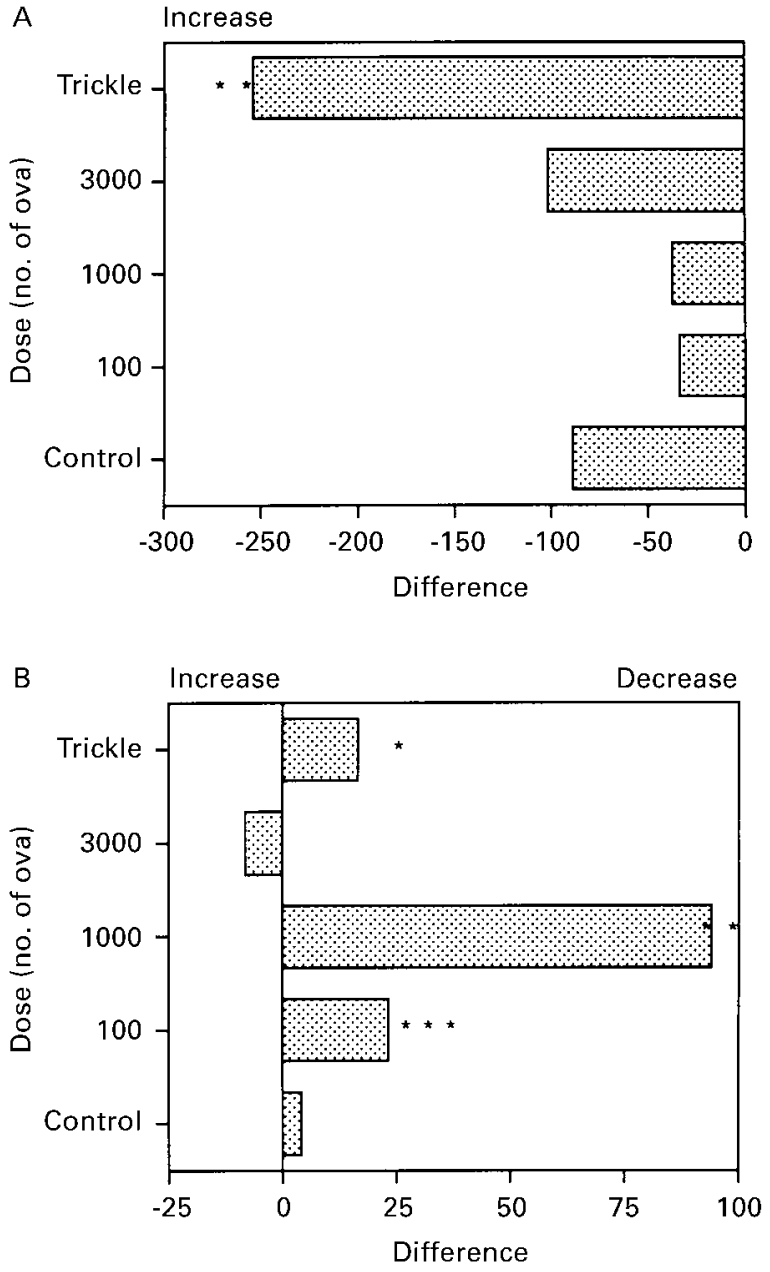

Fig. 4. The mean difference in the time spent immobile for each dose group pre- and post-infection with Toxocara canis by LACA mice (A) and NIH mice (B). ${ }^{*} P \leq 0.05 ;{ }^{* *} P \leq 0.01 ;{ }^{* * *} P \leq 0.001$.

$(P \leq 0.0168)$. Digging showed several changes postinfection with a small increase in the control, low and moderate dose groups and a decrease in the trickle. NIH mice also climbed more post-infection and this was particularly pronounced for the low, moderate and trickle infection groups and the low and moderate larval intensity groups.

Differences in short and long bouts were also observed post-infection with long bouts for immobility showing a reduction particularly for the 100 and 1000 dose groups compared to the control and the $3000(P \leq$ 0.03 ) and for the moderate intensity group compared to the low intensity group $(P \leq 0.0167)$. In contrast to the observations on total time spent ambulating, short bouts of this activity increased post-infection in all dose groups except the 3000 dose, which decreased $(P \leq$ $0.0002)$. This was also observed for the moderate larval intensity group compared to the control $(P \leq 0.002)$. Short and long bouts of both rearing and digging
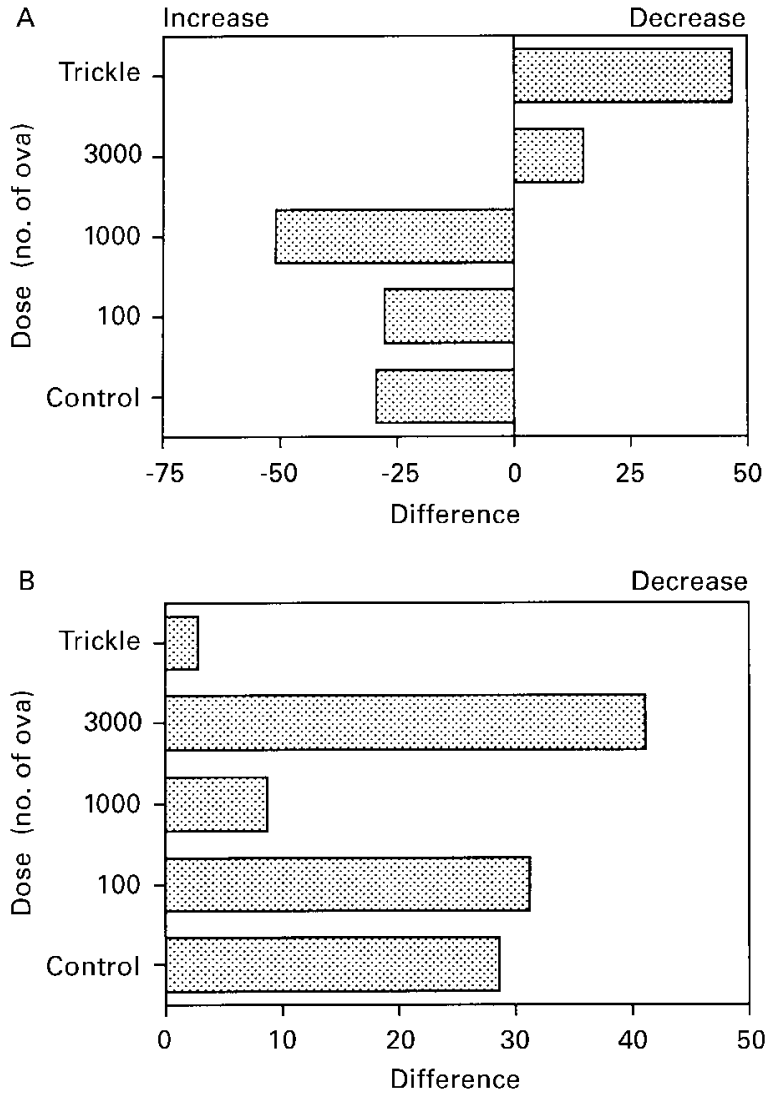

Fig. 5. The mean difference in the time spent ambulating for each dose group pre- and post-infection with Toxocara canis by LACA mice (A) and NIH mice (B).

differed significantly between mouse groups post-infection (table 3). Short bouts of rearing generally increased post-infection except for the 3000 dose group $(P \leq$ $0.0003)$ and the moderate larval intensity group $(P \leq$ 0.02 ) which both showed a significant reduction compared to all other groups. Bouts of digging showed an increase post-infection although most of this effect came from an increase in the control group compared to the infected groups. Bouts of climbing also showed an increase post-infection and this was marked for the 100, 1000 and trickle doses compared to the $3000(P \leq 0.03)$ for short bouts and the 100 and trickle doses compared to the 3000 and control for long bouts $(P \leq 0.01)$.

\section{Differences in the activity by LACA and NIH mice pre- and post-infection}

Firstly, trends in the differences between pre- and post-infection measures of activity by dose are shown in figs 3-8. For some behaviours, the differences between LACA and NIH mice are significantly different particularly so for immobility where all LACA mouse groups showed an increase whereas for NIH mice a decrease 

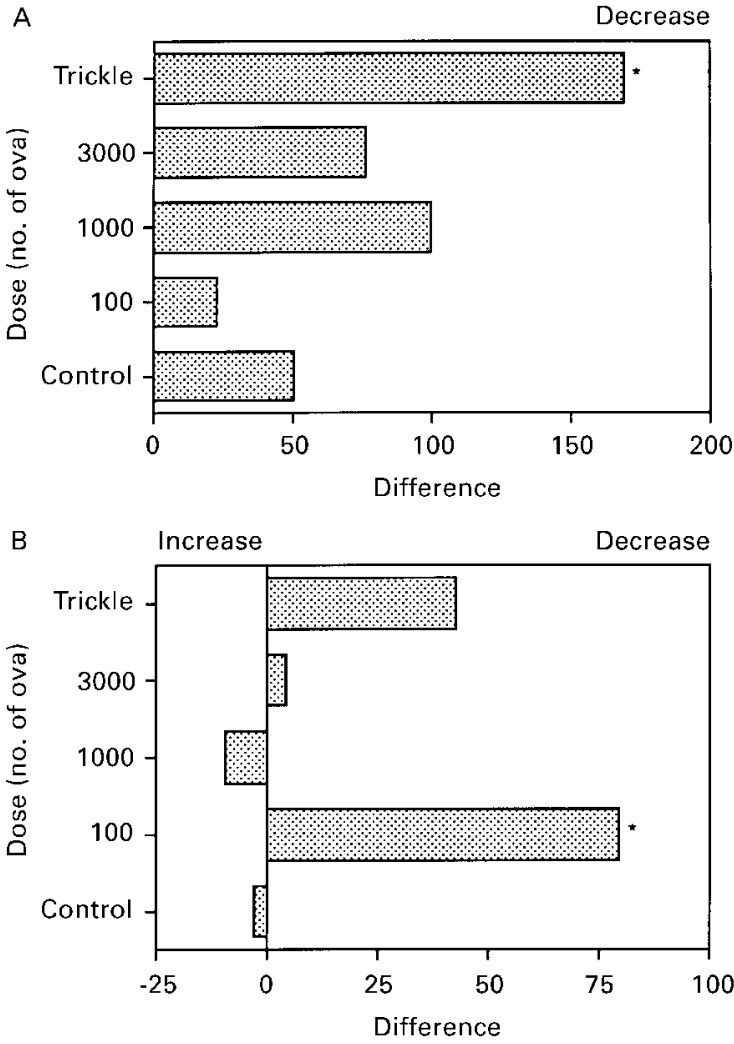

Fig. 6. The mean difference in the time spent rearing for each dose group pre- and post-infection with Toxocara canis by LACA mice $(\mathrm{A})$ and NIH mice $(\mathrm{B}) .{ }^{*} \mathrm{P} \leq 0.05$.

was observed except for a minor increase for the 3000 dose (fig. 4). For climbing, the reverse is true with all groups of LACA mice showing a decrease and all groups of NIH mice an increase (fig. 8). For ambulation, the trend for NIH mice is clear cut with all groups showing a decrease whereas for LACA mice the trickle and 3000 dose showed a decrease whereas the other three groups showed an increase (fig. 5).

Analysis of variance of the mean differences by dose and larval intensity revealed few statistically significant differences for LACA mice (table 2). Differences in short and long bouts of immobility differed significantly by dose, which confirmed the findings of post-infection bouts outlined earlier. For NIH mice, significant differences in mean differences for immobility, digging and climbing were observed between the groups (table 3). For immobility, the trend was a decrease (except for the 3000 dose) whereas for digging and climbing the trend was an increase (with the exception of the trickle group and the low larval intensity group for digging). The difference in short bouts for ambulation, rearing and digging and the difference for long bouts for immobility and climbing confirmed the trends observed for post-infection short and long bouts for these behaviours.
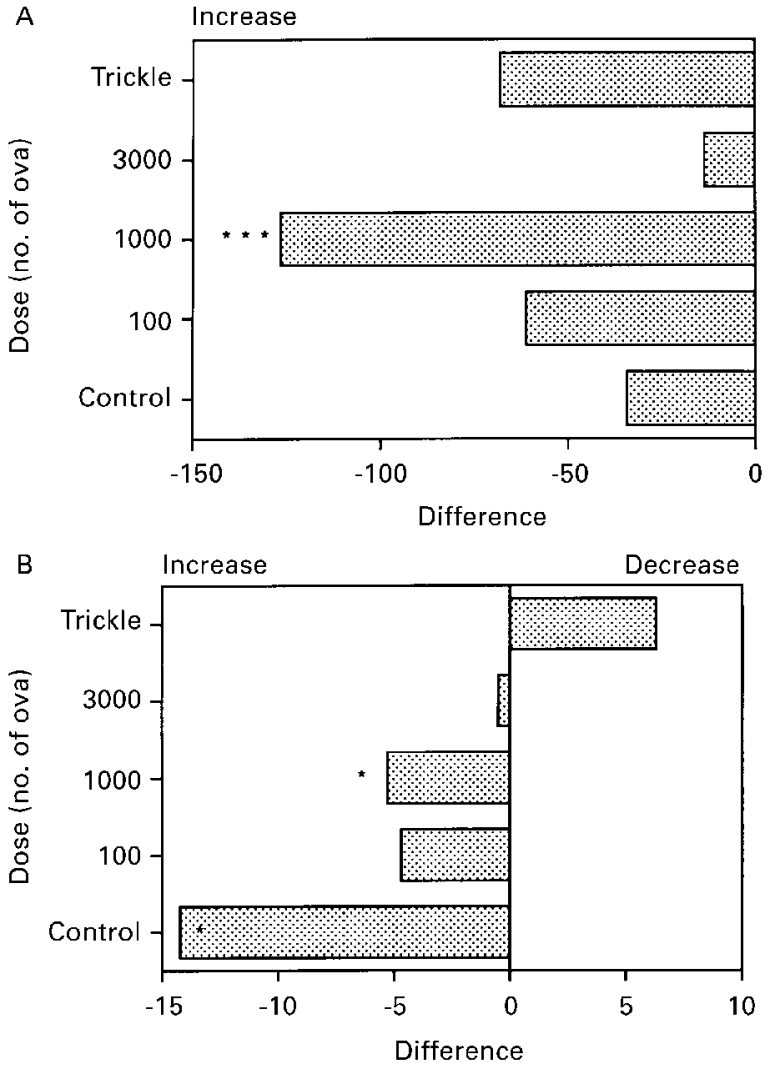

Fig. 7. The mean difference in the time spent digging for each dose group pre- and post-infection with Toxocara canis by LACA mice (A) and NIH mice (B). ${ }^{*} P \leq 0.05 ;{ }^{* * *} P \leq 0.001$.

\section{Discussion}

Larval numbers of $T$. canis recovered from the brains of an inbred and an outbred strain of mouse were generally low as a percentage of dose with the highest recovery from the 3000 dose for LACA mice and 100 dose for $\mathrm{NIH}$ mice. The numbers of larvae recovered from $\mathrm{NIH}$ mice were lower and significantly so for the 1000 , 3000 and trickle doses. The recovery from the trickle dose in NIH mice was markedly lower than that for LACA mice. A differential immune response on the part of the NIH mice may have influenced the resultant burden of larvae in the brain. Epe et al. (1994) compared the larval migration and pathogenicity of T. canis in four inbred and one outbred strain of mice. The highest larval counts in the brain were observed in inbred BALB mice but histological and pathophysiological changes were less pronounced in this strain compared to other strains. It should be noted that infected mice of the BALB and DBA strains reacted completely differently despite being equipped with the same MHC haplotype. Previous work has shown that in the LACA strain most larvae have left the other tissues and accumulated in the brain by day 26 post-infection and that there is significant variation in larval burden between individual mice 
A

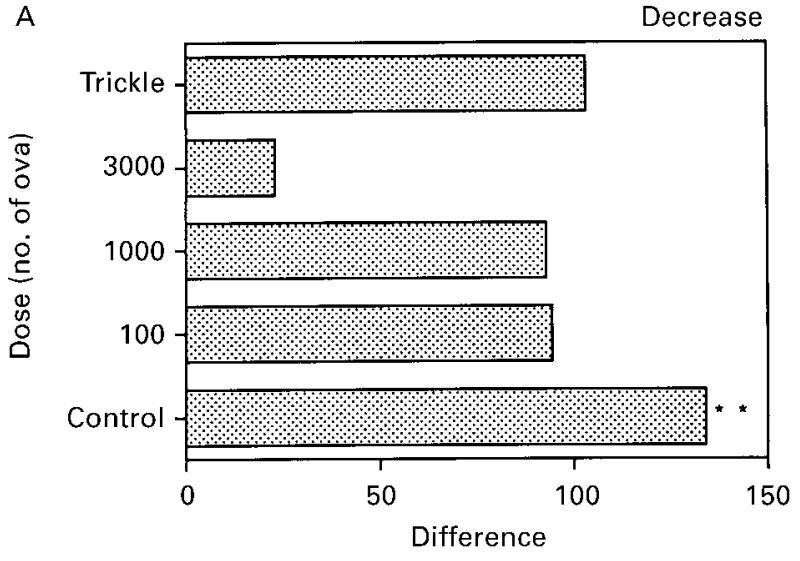

B

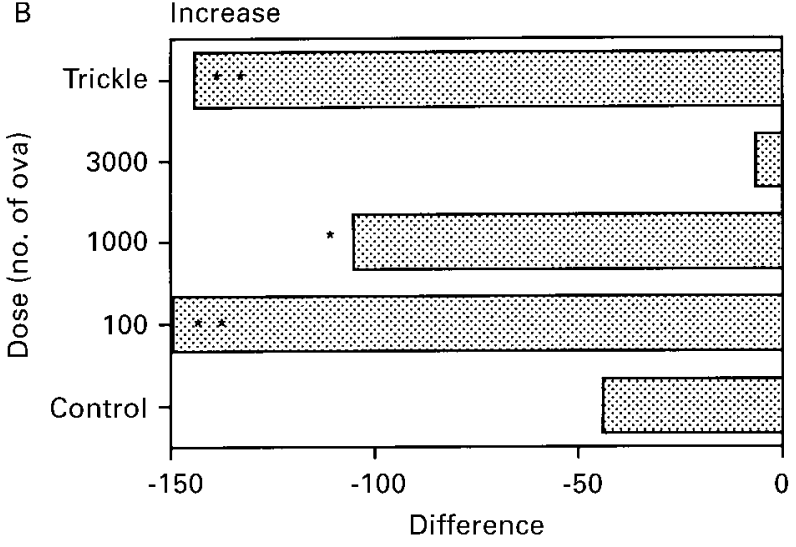

Fig. 8. The mean difference in the time spent climbing for each dose group pre- and post-infection with Toxocara canis by LACA mice (A) and NIH mice (B). ${ }^{*} P \leq 0.05 ;{ }^{* *} P \leq 0.01$.

which received the same dose of ova (Skerrett \& Holland, 1997). This observation is less apparent amongst NIH mice.

Pre-infection, the two strains of mice differed in their baseline activity with outbred LACA mice displaying more immobility and some digging whereas inbred NIH mice were far less immobile and virtually never dug. It is not unusual for different strains of mice to display different behaviours as indicated by Van Oortmerssen (1971) and as reviewed by Wimer \& Fuller (1975). In addition, different groups of mice exhibited significant variation in certain behaviours at baseline, i.e. prior to infection. Most studies would assume that control and experimental animals would perform to a similar baseline before infection. The results from this study indicate that that is not necessarily the case and that measuring behaviour pre-infection may highlight parasite-induced effects which would be otherwise overlooked.

Post-infection, the differences between the two strains were still manifested. LACA mice who received the 3000 and trickle doses showed significant increases in immobility and reductions in ambulation. Therefore, for LACA mice, infection influenced only one goal-directed behaviour and only at the higher and trickle doses. Immobility would not be considered to be purposeful and increased levels would indicate a decrease in exploration. These effects at the 3000 and trickle doses are likely to be a consequence of debilitation due to the side effects of intense infection. In contrast, NIH mice showed an increase in climbing and a decrease in immobility compared to infection levels. Climbing would be considered to be explorative and adaptive to survival in contrast to immobility. These results may indicate that $\mathrm{NIH}$ mice are experiencing less debilitation as a consequence of the lower brain burden of Toxocara larvae compared to the LACA mice.

The primary purpose of measuring bout length related to the observations of Hay et al. (1986) who proposed that mice infected with a 1000 dose of T. canis performed greater numbers of short bouts of behaviour which was indicative of hyperactivity. Larger numbers of short bouts would be indicative of a deficit in the attention of the mouse whereas longer bouts of rearing, ambulation and digging would be considered to be more adaptive with respect to exploration as information gained would be more likely to be retained. Behavioural differences between the strains of mice and between the groups of mice were also observed for short and long bouts of behaviour. There was more variation in the number of bouts pre-infection for LACA mice compared to NIH. Post-infection there was no evidence of hyperactivity among LACA mice; in fact only short and long bouts of immobility increased post-infection. In contrast, for NIH mice, the difference in short bouts before and after infection differed significantly for ambulation, rearing and digging with increases in short bouts for ambulation and rearing with the exception of the 3000 dose group and increases in short bouts of digging with the exception of the trickle group. Therefore, it can be concluded that the effect of infection in LACA mice, particularly at high doses and larval burdens, is debilitation manifested as immobility. In contrast, the effect of infection on NIH mice, which carry lower burdens of larvae in their brain, is to increase certain activities and short bouts of these activities, which is indicative of hyperactivity (although it should be noted that these effects are not always apparent at higher dose levels). Both types of effects could have implications for parasite transmission as outlined by Rau (1983) and Hay et al. (1986).

The results of other studies on activity in T. canisinfected mice have provided contrasting results. This is not surprising given that activity level is very sensitive to environmental and endogenous stimuli. Dolinsky et al. (1981) measured activity levels of Binghamton heterogeneous mice infected with 1000 dose of T. canis ova in the open field and found that infected mice were less active compared to controls. In contrast, work by Hay and colleagues using STR strain mice infected with 1000 dose of larvae found that mice tested in the open field were significantly more active compared to controls (Hay \& Aitken, 1984) and that infected mice exhibited significantly more short bouts of activity compared to controls (Hay et al., 1986). Using exactly the same parameter, activity in the running wheel, Hay et al. (1985) reported more activity in infected mice compared to controls whereas Dolinsky et al. (1981) found this behaviour to be markedly reduced in infected mice. 
Festing \& Greenwood (1976) reported that strain and age differences in mice can influence wheel running.

The present study, using exactly the same protocol for both strains of mice reveals an important difference which may explain observed differences in activity by strain, that is larval burden in the brain. Time did not permit the examination of other tissues for the presence of larvae but the results do indicate that the progress of larval migration may differ between the two strains and that this may effect observed changes in activity.

To conclude, the results concerning behavioural activity in mice presented here highlight the following issues, which have implications for experimental design of studies concerning parasite-altered host behaviour. Firstly, baseline behaviour differs between different strains of mice. Secondly, pre-infection there is quite a lot of variability in activity between individual mice and groups of mice. Thirdly, both pre- and post-infection behaviour was analysed in two ways by dose given and by the larval intensity of the brain. The resulting differences between the groups generally showed the same trends but did show differences in their magnitude and statistical significance. This trend differs from that observed when the measurement of more specific behaviours such social behaviour and anxiety was made in Toxocara-infected mice where larval burden was a more significant predictor of behavioural change compared to dose administered (Cox \& Holland, 1998).

\section{Acknowledgements}

The authors are very grateful to Peter Stafford for his excellent technical assistance. This research was partly funded by the Irish American Partnership.

\section{References}

Barnard, C.J. \& Behnke, J.M. (1990) Parasitism and host behaviour. London, Taylor and Francis.

Burren, C.H. (1971) The distribution of Toxocara canis larvae in the central nervous system of the mouse. Transactions of the Royal Society of Tropical Medicine and Hygiene 65, 450-453.

Cox, D. \& Holland, C.V. (1998) The relationship between numbers of larvae recovered from the brain of Toxocara canis infected mice and social behaviour and anxiety in the host. Parasitology 116, 579-594.

Dolinsky, Z.S., Burright, R.G., Donovick, P.J., Glickman, L.R., Babish, J., Summers, B. \& Cypess, R.H. (1981) Behavioural effects of lead and Toxocara canis in mice. Science 213, 1142-1144.

Dunsmore, J.D., Thompson, R.C.A. \& Bates, I.A. (1983) The accumulation of Toxocara canis larvae in the brains of mice. International Journal for Parasitology 13, 517521.

Epe, C., Sabel, T., Schnieder, T. \& Stoye, M. (1994) The behaviour and pathogenicity of Toxocara canis larvae in mice of different strains. Parasitology Research 80, 691695.

Festing, M.F.W. \& Greenwood, R. (1976) Home-cage wheel activity recording in mice. Laboratory Animals 10, 81-85.

Hay, J. \& Aitken, P.P. (1984) Experimental toxocariasis in mice and their effect on behaviour. Annals of Tropical Medicine and Parasitology 78, 145-155.

Hay, J., Aitken, P.P. \& Arnott, M.A. (1985) The effects of Toxocara canis infection on the spontaneous running activity of mice. Annals of Tropical Medicine and Parasitology 79, 221-222.

Hay, J., Kendall, A.T., Aitken, P.P. \& Arnott, M.A. (1986) Toxocara canis infection and hyperactivity. Annals of Tropical Medicine and Parasitology 80, 531-533.

Holland, C.V. (1997) Epidemiology of toxocariasis in Ireland: human, animal and environmental aspects. pp. 52-64 in Holland, C.V. (Ed.) Modern perspectives on zoonoses. Dublin, Royal Irish Academy.

Hutchinson, W.M., Bradley, M., Cheyne, W.M., Wells, B.W.P. \& Hay, J. (1980) Behavioural abnormalities in Toxoplasma-infected mice. Annals of Tropical Medicine and Parasitology 74, 337-345.

Moore, J. \& Gotelli, N.J. (1990) A phylogenetic perspective on the evolution of altered host behaviours: a critical look at the manipulation hypothesis. pp. 193229 in Barnard, C.J. \& Behnke, J.M. (Eds.) Parasitism and host behaviour. London, Taylor and Francis.

Pritchard, M. \& Kruse, G.O.W. (1982) The collection and preservation of animal parasites. $13 \mathrm{pp}$. Lincoln and London, University of Nebraska Press.

Rau, M.E. (1983) The open field behaviour of mice infected with Trichinella spiralis. Parasitology 86, 311318.

Skerrett, H. \& Holland, C.V. (1997) Variation in the larval recovery of Toxocara canis from the murine brain: implications for behavioural studies. Journal of Helminthology 71, 253-255.

Van Oortmerssen, G.A. (1971) Biological significance, genetics and evolutionary origin of variability in behaviour within and between inbred strains of mice (Mus musculus): a behaviour genetic study. Behaviour 38, 1-98.

Wimer, R.E. \& Fuller, J.L. (1975) Patterns of behaviour. pp. 629-648 in Biology of the laboratory mouse. Dover publications.

(Accepted 17 May 2000)

(C) CAB International, 2001 